\title{
Penentuan Cluster Optimum pada Tingkat Pengangguran dan Tingkat Kemiskinan di Jawa Timur Menggunakan Algoritma Fuzzy C-Means
}

\author{
Ari Eko Wardoyo ${ }^{1}$, Nigati Tripuspita ${ }^{2}$ \\ ${ }^{1}$ Jurusan Manajemen Informatika, Fakultas Teknik, Universitas Muhammadiyah Jember, arieko@unmuhjember.ac.id \\ ${ }^{2}$ Jurusan Teknik Informatika, Fakultas Teknik, Universitas Muhammadiyah Jember, nitritaoke@gmail.com
}

Keywords:

Clustering Analysis, Optimization,

Fuzzy C-Means,

Unemployment Data,

Poverty Data,

\begin{abstract}
PT)
There are many methods used in resolving data clustering. One of them is the Fuzzy C-Means (FCM) method, which is a reliable method to solve clustering problems in the East Java region. This study aims to determine the optimum cluster in the East Java region which can help the government to identify problems and assist policymaking in regencies/cities in East Java province. The research process uses data from the central statistical agency, namely the unemployment rate and poverty rate from 2010 to 2015. In this study, the Davies Bouldin Index (DBI) is used as a cluster validation test for determining the optimum cluster. Unemployment rate and poverty rate data were analyzed using RStudio. From the calculation of the FCM method and also the determination of the optimum cluster results obtained in 2 clusters with a DBI value of $1.2759,3$ clusters with a DBI value of $0.9937,4$ clusters with a DBI value of 0.8737 . The optimum cluster is in 4 clusters with a minimum DBI value.
\end{abstract}

\begin{tabular}{l} 
Kata Kunci \\
\hline Analisis Pengelompokkan, \\
Optimasi, \\
Fuzzy C-Means, \\
Data Pengangguran, \\
Data Kemiskinan,
\end{tabular}

\section{Korespondensi Penulis:}

Ari Eko Wardoyo,

Universitas Muhammadiyah Jember,

Jalan Karimata 49 Jember

Email: arieko@unmuhjember.ac.id

\section{PENDAHULUAN}

Upaya menurunkan tingkat pengangguran dan menurunkan tingkat kemiskinan adalah sama pentingnya. Pengangguran dan kemiskinan adalah sebuah contoh permasalahan pembangunan dan sosial kemasyarakatan. Pembangunan sendiri merupakan aspek penting untuk melihat kinerja seberapa efektifnya penggunaan sumber daya yang ada sehingga lapangan kerja dapat menyerap angkatan kerja yang tersedia. Semakin meningkat produksi barang dan jasa maka semakin banyak juga angkatan kerja yang dibutuhkan sehingga tingkat pengangguran dan kemiskinan semakin menurun. Secara teori, masyarakat yang mempunyai pekerjaan dan berpenghasilan serta dapat memenuhi kebutuhan hidupnya, maka dapat dikatakan masyarakat yang tidak miskin.

Jumlah pengangguran akan meningkat dan menurun setiap tahunnya sesuai dengan pertumbuhan penduduk. Menurut data Badan Pusat Statistik (BPS), di Jawa timur sendiri tingkat pengangguran pada tahun 2015 
sekitar 4,47\%, pada tahun 2016 menurun sekitar 4,21\% dan pada tahun 2012 menurun sekitar 4\% [1]. Untuk tingkat kemiskinan pada tahun 2015 sekitar 12,34\%, pada tahun 2016 menurun sekitar 12,05\% dan pada tahun 2017 menurun sekitar 11,77\% [2]. Jika dilihat per kabupatennya pada tahun 2017 pengangguran tertinggi yaitu di Kota Malang sekitar 7,22\% sedangkan kemiskinan tertinggi yaitu kabupaten Sampang sekitar 23,56\% dibanding kabupaten/kota lainnya [3].

Pada penelitian sebelumnya [4]-[6] sudah ada pengetahuan untuk mengetahui kelompok wilayah namun menggunakan atribut atau variabel yang berbeda. Penelitian ini mengelompokkan wilayah berdasarkan tingkat pengangguran terbuka dan tingkat kemiskinan yang dapat membantu pemerintah untuk mengetahui permasalahan dan membantu pengambilan kebijakan wilayah kabupaten/kota di Provinsi Jawa Timur. Penentuan wilayah kota yang memiliki tingkat pengangguran yang tinggi sangat berpengaruh pada tingkat kemiskinan berdasarkan pengetahuan dari jumlah data Badan Pusat Statistik. Karena hal itu, untuk mendapatkan pengetahuan tersebut maka diperlukan suatu proses pengolahan data dengan teknik Data Mining. Teknik Data Mining yang akan digunakan pada penelitian ini menggunakan metode Fuzzy C-Means [7]. Penelitian diharapkan dapat menghasilkan suatu informasi yang dapat meng-cluster atau mengelompokkan sebuah wilayah kabupaten/kota di Jawa Timur.

\section{METODE PENELITIAN}

Metode penelitian dilakukan dengan pendekatan kuantitatif dimana analisanya berupa data-data numeric (angka). Penelitian ini menggunakan metode Algoritma Fuzzy C-Means yang berguna untuk memartisi data berdasarkan pada jarak antara data masukkan dengan pusat kluster terdekat.

\subsection{Penerapan Fuzzy C-Means}

Diagram alur dari metode Fuzzy C-Means yang digunakan berdasarkan pengaruh tingkat pengangguran terhadap tingkat kemiskinan di Jawa Timur, pada umumnya kinerja Fuzzy C-Means adalah sebagai berikut :

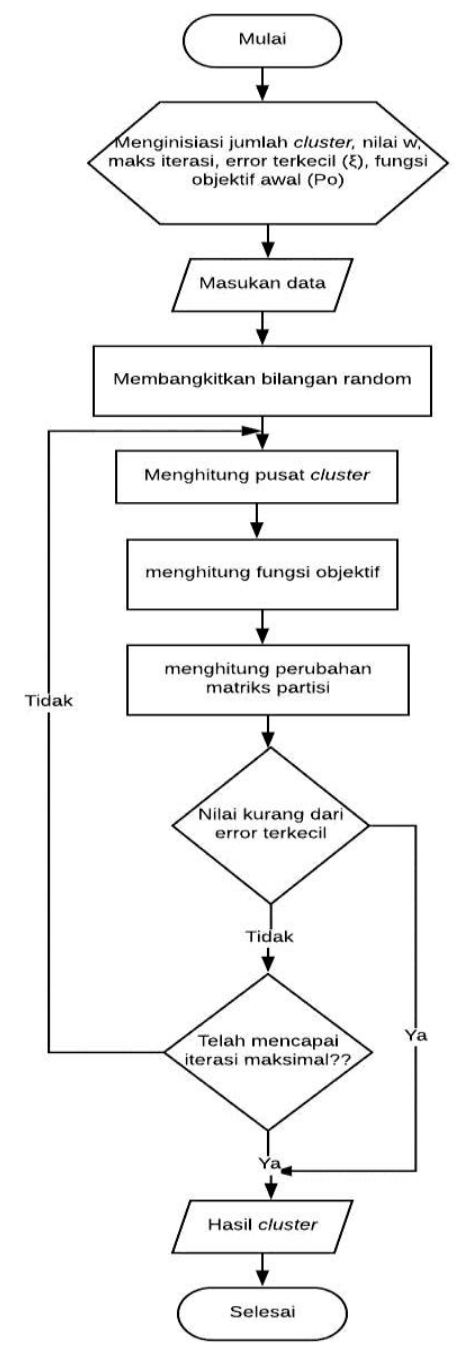

Gambar 1. Flowchart Fuzzy C-Means

Langkah-langkah dalam proses pengelompokan data menggunakan algoritma Fuzzy C-Means adalah: 
1. Menetapkan Matriks partisi awal (U), berupa data tingkat pengangguran dan data tingkat kemiskinan selama enam tahun terakhir. Parameter yang digunakan adalah mulai tahun 2010-2015 dengan menggunakan 10 data sampel. Detail data yang digunakan sebagai berikut:

\begin{tabular}{|c|c|c|c|c|c|c|c|c|c|c|c|c|c|}
\hline $\begin{array}{c}\text { Data } \\
\text { ke }\end{array}$ & $\begin{array}{c}\text { Kabupaten/ko } \\
\text { ta }\end{array}$ & $\begin{array}{c}\text { TPT } \\
\mathbf{2 0 1 0}\end{array}$ & $\mathbf{2 0 1 0}$ & $\mathbf{2 0 1 1}$ & $\mathbf{2 0 1 1}$ & $\mathbf{2 0 1 2}$ & $\mathbf{2 0 1 2}$ & $\mathbf{2 0 1 3}$ & $\mathbf{2 0 1 3}$ & $\mathbf{2 0 1 4}$ & $\mathbf{2 0 1 4}$ & $\mathbf{2 0 1 5}$ & $\mathbf{2 0 1 5}$ \\
\hline 1 & Trenggalek & 2.15 & 15.98 & 3.27 & 14.9 & 2.98 & 14.21 & 4.04 & 13.56 & 4.2 & 13.1 & 2.46 & 13.39 \\
\hline 2 & Kediri & 3.75 & 15.52 & 8.33 & 14.4 & 4.08 & 13.71 & 4.65 & 13.23 & 4.91 & 12.77 & 5.02 & 12.91 \\
\hline 3 & Lumajang & 3.17 & 13.98 & 3.16 & 13 & 4.6 & 12.4 & 2.01 & 12.14 & 2.83 & 11.75 & 2.6 & 11.52 \\
\hline 4 & Banyuwangi & 3.92 & 11.25 & 6.06 & 10.5 & 3.41 & 9.97 & 4.65 & 9.61 & 7.17 & 9.29 & 2.55 & 9.17 \\
\hline 5 & Probolinggo & 2.02 & 25.22 & 2.8 & 23.5 & 1.92 & 22.22 & 3.3 & 21.21 & 1.47 & 20.44 & 2.51 & 20.82 \\
\hline 6 & Mojokerto & 4.84 & 12.23 & 6.79 & 11.4 & 3.35 & 10.71 & 3.16 & 10.99 & 3.81 & 10.56 & 4.05 & 10.57 \\
\hline 7 & Bojonegoro & 3.29 & 18.78 & 5.7 & 17.5 & 3.42 & 16.66 & 5.81 & 16.02 & 3.21 & 15.48 & 5.01 & 15.71 \\
\hline 8 & Sampang & 1.77 & 32.47 & 2.13 & 30.2 & 1.71 & 27.97 & 4.68 & 27.08 & 2.22 & 25.8 & 2.51 & 25.69 \\
\hline 9 & Kota Malang & 8.68 & 5.9 & 9.74 & 5.5 & 7.96 & 5.21 & 7.73 & 4.87 & 7.22 & 4.8 & 7.28 & 4.6 \\
\hline 10 & Kota Surabaya & 6.84 & 7.07 & 7.81 & 6.6 & 5.27 & 6.25 & 5.32 & 6 & 5.82 & 5.79 & 7.01 & 5.82 \\
\hline
\end{tabular}

Keterangan:

Gambar 2. Data Tingkat Pengangguran dan Tingkat Kemiskinan

- TPT: Tingkat Pengangguran Terbuka

- TK: Tingkat Kemiskinan

2. Menentukan nilai parameter awal

Tabel 1. Parameter Awal

\begin{tabular}{clcl}
\hline No & Keterangan & & Nilai \\
\hline 1 & Jumlah cluster & $\mathrm{c}$ & 3 \\
2 & Pangkat & $\mathrm{w}$ & 2 \\
3 & Maksimum Iterasi & MaxIter & 20 \\
4 & Error terkecil & $\xi$ & 0,001 \\
5 & Fungsi Objektif Awal & $\mathrm{P}_{\mathrm{o}}$ & 0 \\
6 & Iterasi Awal & $\mathrm{t}$ & 1 \\
7 & Fungsi Objektif & $\mathrm{P} 1$ & $5.545,94$ \\
8 & $\mathrm{P}_{\mathrm{t}}-\mathrm{P}_{\mathrm{t}-1}$ & & $5.545,94$ \\
\hline
\end{tabular}

3. Membangkitkan bilangan random sebagai data derajat keanggotaan awal untuk elemen matriks partisi awal (U). Berikut hasilnya:

Tabel 2. Bilangan Random

\begin{tabular}{cccc}
\hline No & C1 & C2 & C3 \\
\hline 1 & 0,441 & 0,490 & 0,069 \\
2 & 0,556 & 0,385 & 0,059 \\
3 & 0,156 & 0,307 & 0,537 \\
4 & 0,461 & 0,075 & 0,464 \\
5 & 0,427 & 0,216 & 0,357 \\
6 & 0,096 & 0,285 & 0,619 \\
7 & 0,329 & 0,399 & 0,272 \\
8 & 0,020 & 0,467 & 0,514 \\
9 & 0,311 & 0,348 & 0,341 \\
10 & 0,321 & 0,538 & 0,140 \\
\hline
\end{tabular}

4. Menentukan pusat cluster pada iterasi awal

$$
\begin{aligned}
\mathrm{V}_{\mathrm{kj}} & =\frac{\sum_{i=1}^{n}\left(\left(\mu_{i k}\right)^{w} * X_{i j}\right)}{\sum_{i=1}^{n}\left(\mu_{i k}\right)^{w}} \\
\mathrm{~V}_{\mathrm{kj}} & =\frac{\left((0,441)^{2} * 2,15\right)}{0,441^{2}} \\
\mathrm{~V}_{\mathrm{kj}} & =\frac{0,194481 * 2,15}{0,194481}=2,15
\end{aligned}
$$


5. Menghitung fungsi objektif (P)

$$
\begin{aligned}
& \mathrm{P}_{1.1}=\sum_{i=1}^{n} \sum_{k=1}^{c}\left(\left[\sum_{j=1}^{m}\left(X_{i j}-V_{k j}\right)^{2}\right]\left(\mu_{i k}\right)^{w}\right. \\
& \mathrm{P}_{1.1}=\left((2,15-3,8734)^{2}+(15,98-15,0629)^{2}+(3,27-6,0587)^{2}+(14,9-14,0256)^{2}+(2,98-\right. \\
& 3,8247)^{2}+(14,21-13,3242)^{2}+(4,04-3,7024)^{2}+(13,56-12,7862)^{2}+(4,2-4,7390)^{2}+(13,1- \\
& \left.12,3504)^{2}+(2,46-4,1135)^{2}+(13,39-12,4684)^{2}\right) *(0,441)^{2} \\
& \mathrm{P}_{1.1}=3,6950 \\
& \mathrm{P}_{\text {tot }}=\mathrm{P}_{1.1}+\mathrm{P}_{1.2}+\mathrm{P}_{1.3} \\
& \mathrm{P}_{\text {tot }}=3,6950+3,5733+0,0612=7,3294
\end{aligned}
$$

Tabel 3. Fungsi Objektif (P) Iterasi 1

\begin{tabular}{cllll}
\hline Data & P-1.1 & P-1.2 & P-1.3 & P Tot \\
\hline 1 & 3,6950 & 3,5733 & 0,0612 & 7,3295 \\
2 & 3,3803 & 4,0541 & 4,6292 & 12,0636 \\
3 & 1,0685 & 93,7222 & 287,4253 & 382,2160 \\
4 & 157,7353 & 4,2084 & 159,5884 & 321,5321 \\
5 & 549,7745 & 141,3352 & 384,2248 & 1075,3345 \\
6 & 7,9084 & 69,8954 & 329,4847 & 407,2886 \\
7 & 195,3573 & 286,5817 & 133,8407 & 615,7797 \\
8 & 1,8637 & 1057,5684 & 1279,2094 & 2338,6415 \\
9 & 54,1647 & 67,4899 & 64,9133 & 186,5679 \\
10 & 50,0041 & 139,6609 & 9,5185 & 199,1835 \\
Fungsi Objektif (P1) & & & 5545,9367 \\
\hline
\end{tabular}

6. Menghitung perubahan matriks partisi

$$
\begin{aligned}
& \mu_{i k}=\frac{\left[\sum_{j=1}^{m}\left(X_{i j}-V_{k j}\right)^{2}\right]^{\frac{-1}{w-1}}}{\sum_{k=1}^{c}\left[\sum_{j=1}^{m}\left(X_{i j}-V_{k j}\right)^{2}\right]^{\frac{-1}{w-1}}} \\
& \mu_{i k}=\frac{3,6950}{7,3295}=0,5041
\end{aligned}
$$

Tabel 4. Derajat Keanggotaan Iterasi 1

\begin{tabular}{ccccccc}
\hline Data & $\mu 1$ & $\mu 2$ & $\mu 3$ & $\mathrm{C} 1$ & $\mathrm{C} 2$ & $\mathrm{C} 3$ \\
\hline 1 & 0,5041 & 0,4875 & 0,0084 & $\mathrm{OK}$ & & \\
2 & 0,2802 & 0,3361 & 0,3837 & & & OK \\
3 & 0,0028 & 0,2452 & 0,7520 & & & OK \\
4 & 0,4906 & 0,0131 & 0,4963 & & & OK \\
5 & 0,5113 & 0,1314 & 0,3573 & OK & & \\
6 & 0,0194 & 0,1716 & 0,8090 & & & OK \\
7 & 0,3173 & 0,4654 & 0,2174 & & OK & \\
8 & 0,0008 & 0,4522 & 0,5470 & & & OK \\
9 & 0,2903 & 0,3617 & 0,3479 & & OK & \\
10 & 0,2510 & 0,7012 & 0,0478 & & OK & \\
\multicolumn{7}{c}{ Total } \\
\hline \multicolumn{7}{c}{}
\end{tabular}

7. Memeriksa kondisi berhenti Iterasi akan berhenti apabila memenuhi syarat berikut:

- Jika $\left(\left|P_{t}-P_{t-1}\right|<\xi\right)$ atau ( $\mathrm{t}>$ MaxIter) maka berhenti, artinya jika hasil pengurangan dari fungsi objektif dan fungsi objektif awal kurang dari error terkecil atau iterasi awal lebih dari maksimal iterasi maka akan berhenti

- Jika tidak $\mathrm{t}=\mathrm{t}+1$ maka mengulang kembali tahap/langkah ke empat

Tabel 5. Ketentuan Berhenti

\begin{tabular}{ll}
\hline Ketentuan Berhenti & \\
\hline Jika $\left(\left|P_{t}-P_{t-1}\right|<\xi\right)$ & Lanjut \\
$(\mathrm{t}>$ MaxIter & Lanjut \\
\hline
\end{tabular}


Karena $\left|P_{t}-P_{t-1}\right|=|5,545,94-0|=5,545,94>$ error terkecil maka tidak berhenti dan dilanjutkan pada iterasi selanjutnya hingga $\mathrm{P}_{\mathrm{t}}-\mathrm{P}_{\mathrm{t}-1}<$ error terkecil atau iterasi awal lebih dari maksimal iterasi. Pada proses uji coba ini berhenti pada iterasi 14.

\subsection{Proses Davies Bouldin Index}

Penentuan cluster optimum pada penelitian ini menggunakan Davies-Bouldin Index, dengan jumlah 10 data sampel dengan hasil terbaik.

1. Mengelompokkan data berdasarkan cluster yang diikuti

Menghitung DBI pada Fuzzy C-Means menggunakan hasil dari pusat cluster yang kemudian dikelompokkan sesuai dengan hasil derajat keanggotaan

2. Menentukan nilai perhitungan kerapatan (density) data pada cluster atau Sum of Square Within (SSW)

3. Melakukan perhitungan untuk nilai separasi atau Sum of Square Between (SSB)

4. Menghitung nilai rasio yang diperoleh

\section{HASIL DAN ANALISIS}

Penerapan clustering dengan Fuzzy C-Means akan dibahas secara runtut pada bab ini. Data yang telah diperoleh akan diolah untuk mendapatkan hasil cluster optimum menggunakan Davies Bouldin Index. Data yang digunakan adalah data tingkat pengangguran terbuka dan tingkat kemiskinan di Provinsi Jawa Timur Periode 20102015 .

\subsection{Penerapan Fuzzy C-Means}

a. Dua Cluster

Perhitungan untuk 2 cluster berhenti pada iterasi ke-70 dan error terkecil adalah 0,001.

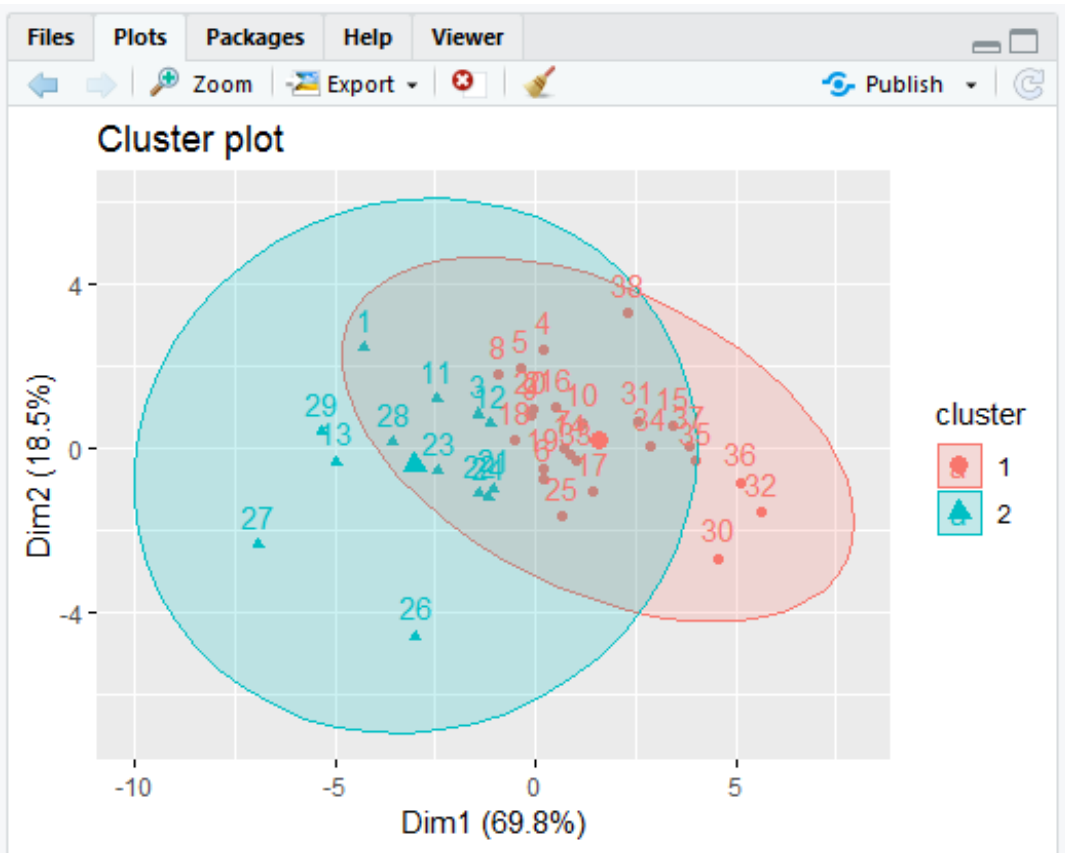

Gambar 3. Grafik Plot Untuk 2 Cluster

b. Tiga Cluster

Perhitungan untuk 3 cluster berhenti pada iterasi ke-64 dan error terkecil adalah 0,001. 


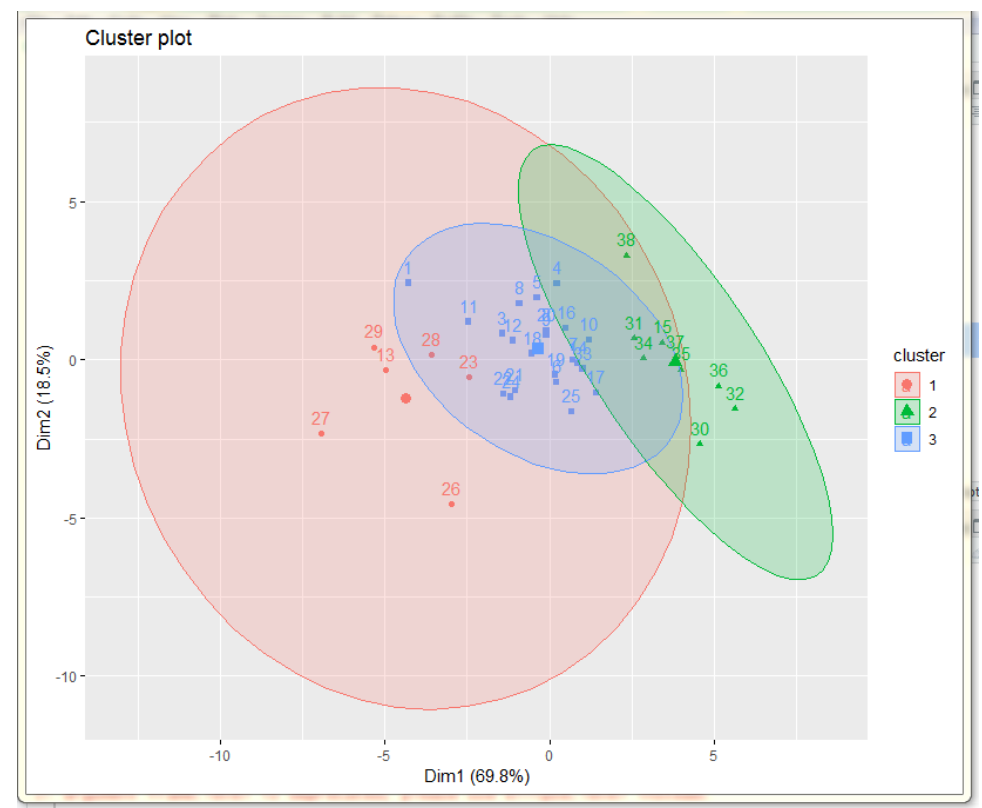

Gambar 4. Grafik Plot Untuk 3 Cluster

c. Empat Cluster

Perhitungan untuk 4 cluster berhenti pada iterasi ke-68 dan error terkecil adalah 0,001.

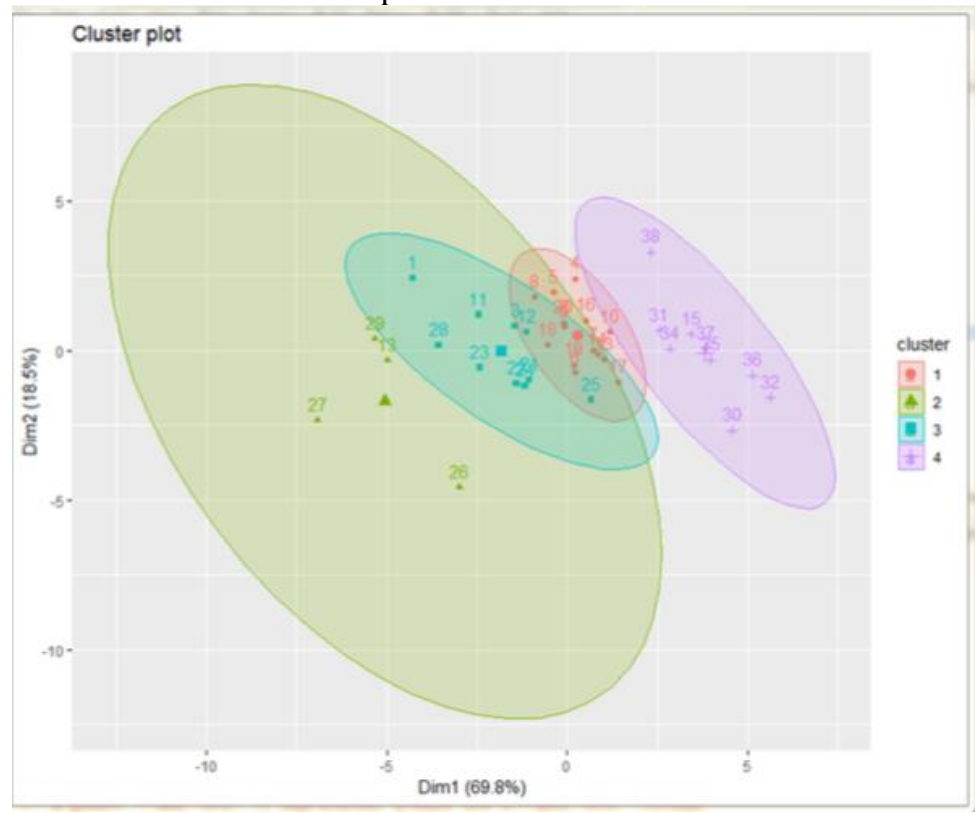

Gambar 5. Grafik Plot Untuk 4 Cluster

\subsection{Penentuan Cluster Optimum}

Berdasarkan ketiga jumlah cluster (2 cluster, 3 cluster, dan 4 cluster) maka akan dicari nilai cluster optimum.

1. Proses Davies Bouldin Index untuk 2 Cluster

- Menentukan nilai perhitungan kerapatan (density) data pada cluster atau Sum of Square Within (SSW)

Tabel 6. SSW Untuk 2 Cluster

\begin{tabular}{ll}
$\mathrm{SSW}_{1}$ & 1867,114 \\
\hline $\mathrm{SSW}_{2}$ & 1441,282 \\
\hline
\end{tabular}

- Mencari nilai separasi atau Sum of Square Between (SSB)

SSB $=4257,61$

- Nilai rasio yang diperoleh

$\mathrm{DBI}=1,2759$ 
2. Proses Davies Bouldin Index untuk 3 Cluster

- Menentukan nilai perhitungan kerapatan (density) data pada cluster atau Sum of Square Within (SSW)

Tabel 7. SSW Untuk 3 Cluster

\begin{tabular}{ll}
\hline $\mathrm{SSW}_{1}$ & 480,1896 \\
\hline $\mathrm{SSW}_{2}$ & 223,8220 \\
\hline $\mathrm{SSW}_{3}$ & 102,2332 \\
\hline
\end{tabular}

- $\quad$ Mencari nilai separasi atau Sum of Square Between (SSB)

$\mathrm{SSB}=5475,362$

- $\quad$ Nilai rasio yang diperoleh

$\mathrm{DBI}=0,9937$

3. Proses Davies Bouldin Index untuk 4 Cluster

- Menentukan nilai perhitungan kerapatan (density) data pada cluster atau Sum of Square Within (SSW)

Tabel 8. SSW Untuk 3 Cluster

\begin{tabular}{ll}
\hline $\mathrm{SSW}_{1}$ & 353,3696 \\
\hline $\mathrm{SSW}_{2}$ & 217,1700 \\
\hline $\mathrm{SSW}_{3}$ & 290,5308 \\
\hline $\mathrm{SSW}_{4}$ & 223,8220 \\
\hline
\end{tabular}

- $\quad$ Mencari nilai separasi atau Sum of Square Between (SSB)

$\mathrm{SSB}=6217,408$

- $\quad$ Nilai rasio yang diperoleh

$\mathrm{DBI}=0,8737$

4. Hasil DBI Untuk Mencari Cluster Optimum

Semakin kecil nilai Davies Bouldin Index yang diperoleh maka semakin baik cluster yang diperoleh dari pengelompokan. Maka untuk cluster optimum pada tingkat pengangguran dan tingkat kemiskinan di Jawa Timur menggunakan 4 cluster

Tabel 9. Hasil Nilai DBI

\begin{tabular}{ll}
\hline Cluster & DBI \\
\hline 2 & 1,2759 \\
\hline 3 & 0,9937 \\
\hline 4 & 0,8737 \\
\hline
\end{tabular}

\section{KESIMPULAN}

Berdasarkan hasil analisis maka dapat disimpulkan bahwa:

1. Penerapan Algoritma Fuzzy C-Means berdasarkan tingkat pengangguran dan tingkat kemiskinan untuk mengelompokkan wilayah kabupaten/kota di Jawa Timur, diperoleh cluster optimum dengan hasil 4 cluster berdasarkan nilai davies bouldin index 0,8737 .

2. Hasil pengelompokan dengan 4 cluster pada :

a. C1 terdapat 15 wilayah terdiri dari Kab. Ponorogo, Kab. Tulungagung, Kab. Blitar, Kab. Kediri, Kab. Malang, Kab. Lumajang, Kab. Jember, Kab. Banyuwangi, Kab. Pasuruan, Kab. Mojokerto, Kab. Jombang, Kab. Nganjuk, Kab. Madiun, Kab. Magetan, Kota Probolinggo

b. C2 terdapat 4 wilayah terdiri dari Kab. Probolinggo, Kab. Bangkalan, Kab. Sampang, Kab. Sumenep

c. C3 terdapat 10 wilayah terdiri dari Kab. Pacitan, Kab. Trenggalek, Kab. Bondowoso, Kab. Situbondo, Kab. Ngawi, Kab. Bojonegoro, Kab. Tuban, Kab. Lamongan, Kab. Gresik dan

d. C4 terdapat 9 wilayah terdiri dari Kab. Sidoarjo, Kab. Kediri, Kab. Blitar, Kota Malang, Kota Pasuruan, Kota Mojokerto, Kota Madiun, Kota Surabaya, Kota Batu. 


\section{REFERENSI}

[1] Badan Pusat Statistik Provinsi Jawa Timur, "Tingkat Pengangguran Terbuka (TPT) Menurut Kabupaten/Kota, 2001 - Agustus 2018.” [Online]. Available:

https://jatim.bps.go.id/dynamictable/2018/11/05/432/tingkat-pengangguran-terbuka-tpt-menurut-kabupatenkota-2001---agustus-2018.html.

[2] Badan Pusat Statistik Provinsi Jawa Timur, "Persentase Penduduk Miskin Menurut Kabupaten/Kota di Provinsi Jawa Timur Tahun 2012-2017.” [Online]. Available:

https://jatim.bps.go.id/statictable/2018/01/30/755/persentase-penduduk-miskin-menurut-kabupaten-kota-diprovinsi-jawa-timur-tahun-2012-2017.html.

[3] Badan Pusat Statistik Provinsi Jawa Timur, "Laporan Eksekutif Keadaan Angkatan Kerja di Jawa Timur Tahun 2011-2012.”

[4] N. Komariyah and M. S. Akbar, "Pengelompokkan Kabupaten/Kota di Provinsi Jawa Timur berdasarkan Indikator Kemiskinan Dengan Metode Cluster Analisis."

[5] M. Widiastuti and E. Yusuf, "Pemetaan Kemiskinan Kabupaten/Kota di Provinsi Jawa Tengah Tahun 2002 dan 2010 Menggunakan Analisis Klaster,” Diponegoro J. Econ., vol. 1, no. 1, pp. 1-14, 2012.

[6] F. Ramdhani et al., "Pengelompokkan Provinsi di Indonesia Berdasarkan Karakteristik Kesejahteraan Rakyat Menggunakan Metode K-Means Cluster,” vol. 4, pp. 875-884, 2015.

[7] Sundar, M. Chitradevi, and G. Geetharamani, "An Analysis On The Performance Of K-Means Clustering Algorithm For Cardiotogram Data Clustering,” Int. J. Comput. Sci. Appl., vol. 2, no. 5, 2012. 